\title{
AC 2012-5477: PORTFOLIOS TO PROFESSORIATE: HELPING STUDENTS INTEGRATE PROFESSIONAL IDENTITIES THROUGH EPORTFOLIOS
}

\section{Dr. Lisa D. McNair, Virginia Tech}

Lisa McNair is an Associate Professor in the Department of Engineering Education at Virginia Tech, where she also serves as Assistant Department Head for Graduate Programs and co-directs the Virginia Tech Engineering Communication Center. Her research includes interdisciplinary collaboration, communication studies, identity theory, and reflective practice. Projects supported by the National Science Foundation include: interdisciplinary pedagogy for pervasive computing design; writing across the curriculum in statics courses; a a CAREER award to explore the use of e-portfolios to promote professional identity and reflective practice. Her teaching emphasizes the roles of engineers as communicators and educators, the foundations and evolution of the engineering education discipline, assessment methods, and evaluating communication in engineering.

\section{Wende Garrison, Virginia Tech}

Wende Garrison is the Director of Curriculum, Assessment, and Communication for Portfolio to Professoriate at Virginia Tech. She received her master's in rhetoric and composition and film and television from Portland State University in 1999. Garrison has been the conference Chair for the Association of American Colleges and Universities' Eportfolio Forum for three years. She is on both the Editorial Board and the Review Board for the International Journal of Eporfolios and on the 2012 program committee for the Association for Authentic, Experiential, and Evidence-Based Learning annual conference. Garrison also served as the VALUE Initiative Manager for AAC\&U, where she facilitated the creation of 15 national rubrics. 


\section{Portfolios to Professoriate: Helping Students Integrate Professional Identities through ePortfolios}

\section{Introduction}

This paper describes the initial stages of a longitudinal project to design, implement, and assess an ePortfolio curriculum that supports graduate engineering students in developing professional identities both as educators and as engineers. It is part of an NSF-funded research study that addresses the major task, articulated in Jamieson \& Lohmann's 2009 report Creating a Culture for Scholarly and Systematic Innovation in Engineering Education ${ }^{1}$, of institutionally prioritizing connections between engineering education research and practice. The purpose of this project is to use electronic portfolios (ePortfolios) to help engineering graduate students achieve the interdisciplinary goal of developing professional identities as both educators and engineers. As the majority of the future professoriate, engineering graduate students should be reflective practitioners who can leverage scholarly teaching approaches to contribute to the cycle of experience, learning and practice.

ePortfolios are digital collections of work that are tied together by reflective text. In various fields, ePortfolios are used extensively to enact meta-cognitive practices of learning development, professional career preparation, and program assessment. This project takes these uses to a new level by exploring how ePortfolios can be used to integrate reflective practice into a range of program models that promote scholarly teaching and engineering education research. ePortfolios are ideally suited to this task because they are flexible, they promote student motivation and ownership, and they can be situated outside of established course structures and even linked with multiple institutions nationwide.

In this paper we report on our initial development and implementation of an ePortfolio curriculum for engineering graduate students. The following sections include: an overview of project activities and rationale that describes the overall objectives of the 5-year project and explains both the medium and the theoretical motivation that serves as a foundation for our activities. This section also includes a description of the settings for implementing the ePortfolio curriculum. Next, we describe the curriculum we have developed and the processes used for its pilot implementation. Then, we outline the assessment methods to be used in the project, including a summary of survey development. Finally, we conclude with a prospectus of areas we hope to describe in the future with analyzed results.

\section{Overview of Project Activities and Rationale}

The overall project involves goals of 1) creating curriculum and assessment methods for implementing ePortfolios in a range of graduate academic settings, and 2) evaluating the implementation of the curriculum in terms of its effectiveness in helping students construct cohesive professional identities as engineers and educators. Both of these goals are grounded in a rationale that privileges student-centered learning. 


\section{A. Project Overview}

The Portfolio to Professoriate (P2P) project has several elements that span a 5-year project of creating, implementing and assessing an ePortfolio process that results in thorough and effective student presentations of their professional identity as both engineers and educators. The P2P project will create, implement and assess:

1. both a 20-week (academic year long) and 10-week (term long) professional ePortfolio curriculum (free and available to the public) that does not require inclusion in a course and can be completed by students, on their own, in less than 45 minutes per week.

2. a set of feedback principles (free and available to the public) for P2P ePortfolios (that can also be applied to other types of ePortfolios).

3. a public ePortfolio gallery of P2P ePortfolios.

4. a rubric for P2P ePortfolios suitable for distribution to students (free and available to the public).

5. a survey to measure student attitudes toward four professional aspects (teaching, research, service, and lifelong learning) both before and after they create ePortfolios.

In this paper, we focus on the initial development and implementation of the 20 -week and 10-week curriculums.

P2P is being implemented on four campuses, each with notably different circumstances. At University A, students are participating over two semesters and are receiving monetary compensation for their participation. At the University B, students are participating over one semester and are volunteering to participate. These students at University B are all a part of an interdisciplinary cohort and attend weekly research group meetings. University C students are also volunteering to participate, also over only one semester, but all student volunteers are taking a class at the same time they are building an ePortfolio. University D students, like University B and C students, are volunteering, over only one semester, but are neither taking a class together nor attending a weekly cohort meeting during the ePortfolio process. However, University D students are required to submit ePortfolios as part of their annual review.

These diverse circumstances will help determine what conditions are necessary for successfully implementing a professional portfolio program like P2P. As data on ideal circumstances for P2P implementation is developed, P2P may test its curriculum again at a new campus in the fall of 2012. 


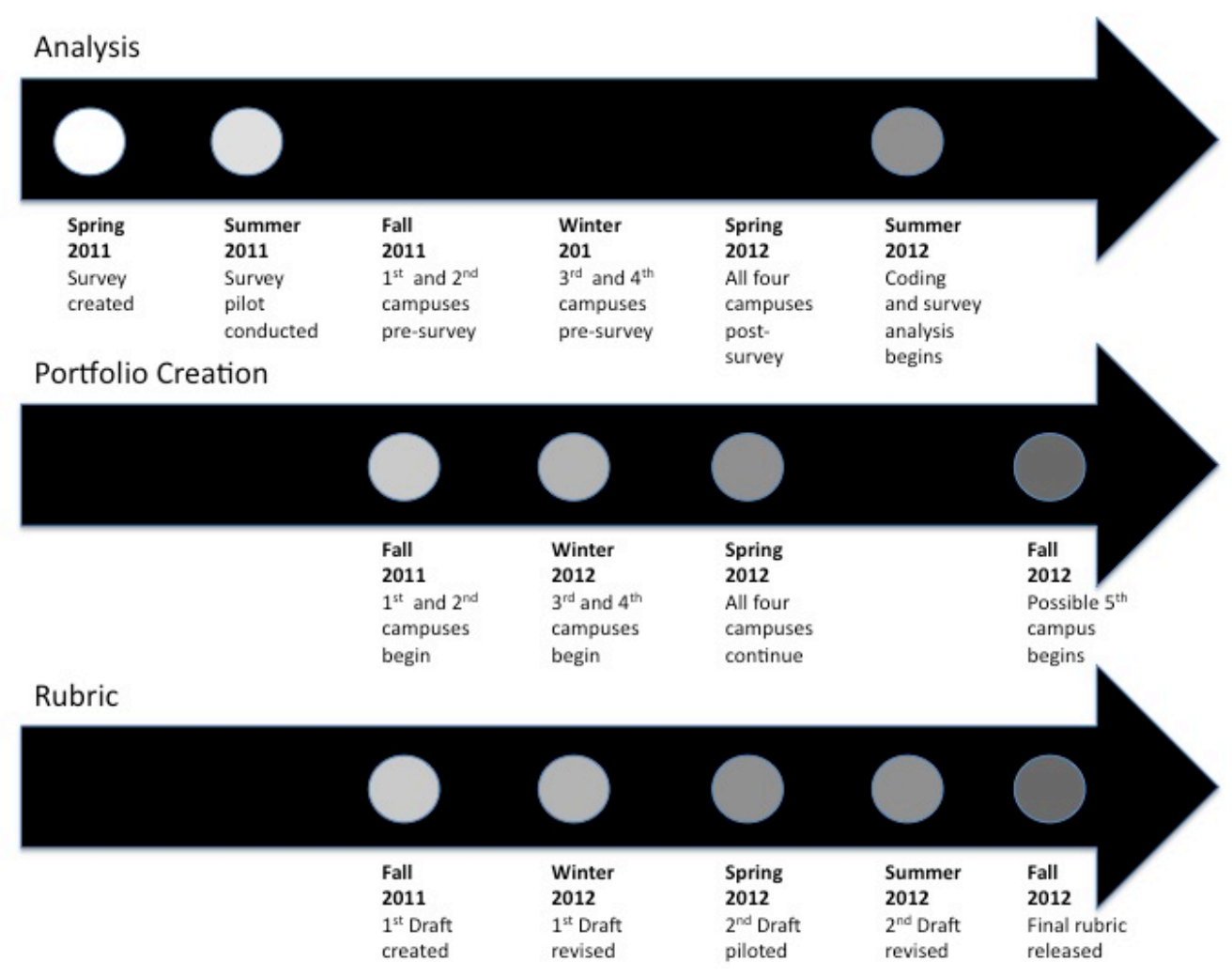

Figure 1. 15-month timeline of initial P2P activities.

Figure 1 shows the timeline for year one activities of P2P, which was funded in January of 2011. The first six months were devoted to survey construction. Over the summer of 2011 , the survey was taken by over 50 students at one of the campuses ${ }^{2}$. As fall term began, the first ePortfolio students started the P2P 20-week curriculum at University A. Fall term also saw the initial development of the P2P rubric. As spring term begins in January of 2012, students on the other three campuses (University B, C, and D) started creating their ePortfolios. Data analysis will take place over the summer of 2012 with a possible fifth campus added in the fall of 2012.

\section{B. Rationale}

ePortfolios have been in use throughout higher education for nearly two decades. Based on many of the practices found in paper portfolios (collections of best work, shared with an audience, showcasing progress over time, etc.), ePortfolios bring additional advantages based on the technology they utilize.

A number of technology vendors have emerged recently, most providing ePortfolio systems that allow students to-freely or for a fee-create an account, log in and start building an ePortfolio. But in the early days of ePortfolios, the most common technology used was website building tools. Through programs like Google Sites, these same tools-now considerably more evolved-are still being used to create ePortfolios. 
One factor in choosing an ePortfolio tool is the consideration of student ownership. When the student owns the ePortfolio and it is portable beyond the educational institution, the student is more likely to deeply engage in the ePortfolio, spending additional time and energy because the ePortfolio is theirs to control, share, and add to over their lifetime.

When creating an ePortfolio using a website building tool, a student typically creates a page for each subject or goal area (for instance: teaching, research, and service) and uploads evidence of their accomplishments to those subject pages (through attachments to the webpage itself or through links to online evidence). The webpage for each subject can also contain the reflection on the evidence uploaded. ePortfolio viewers and readers, then, can navigate an ePortfolio the same way they navigate a website-exploring links and deeper levels of pages and information-according to their interest.

Creating a portfolio always has benefits, often documenting and illustrating both talent and roles the student was previously unaware of. But putting a portfolio online (or creating an "ePortfolio") allows the creator to do several things the paper portfolio fails to do. These include: using resource links to showcase some accomplishments more thoroughly (e.g., see example in Figure 2); pointing out the integration of items and themes across the portfolio (e.g., see example in Figure 3); and sharing a virtual portfolio with multiple readers simultaneously.

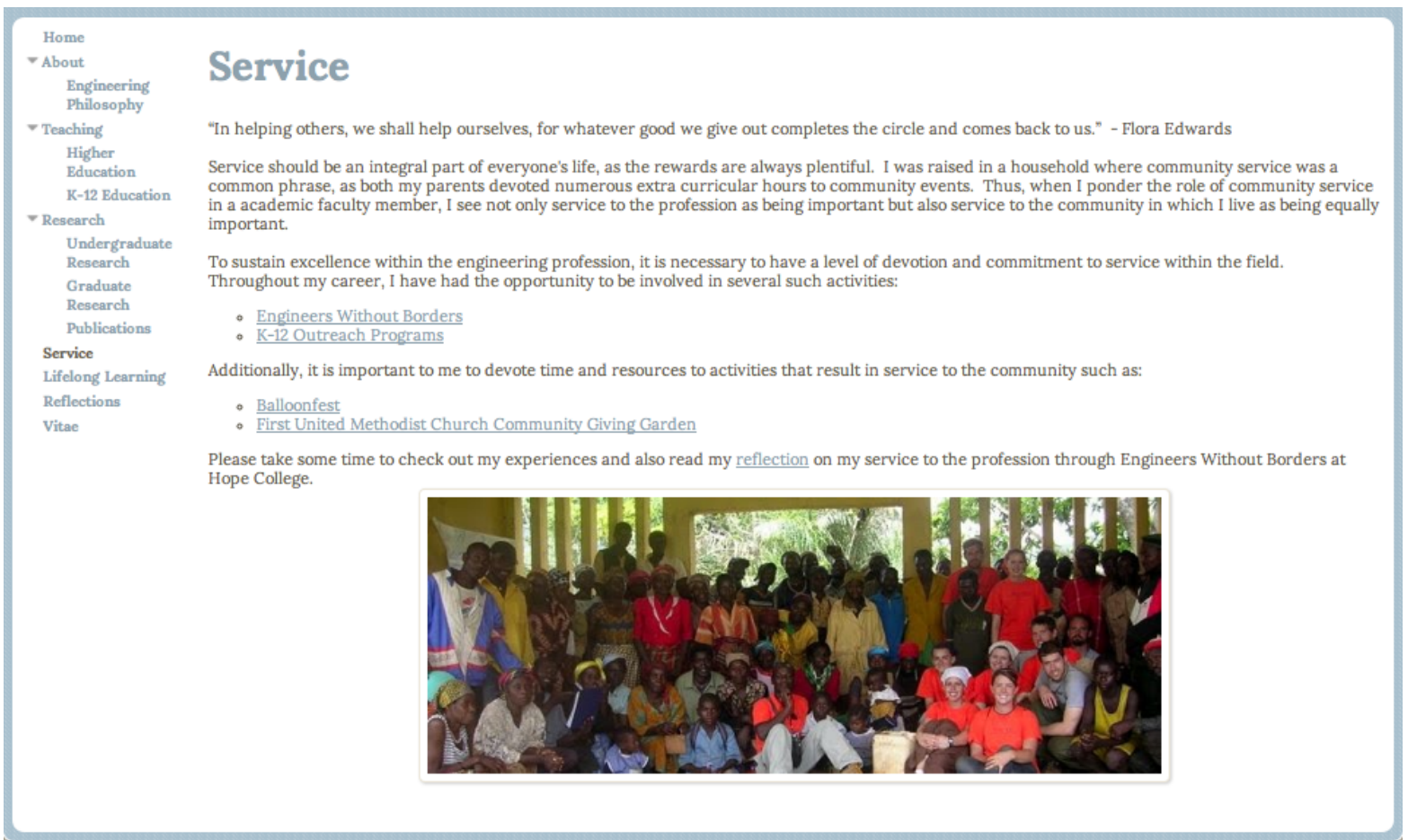

Figure 2. Example of ePortfolio page using resource links to showcase accomplishments more thoroughly (Peckens, https://sites.google.com/site/cpeckensportfolio/service).

Because an ePortfolio is online, creating links throughout it is tremendously easy. This ability to link to websites and other online resources allows the student to use evidence 
that would often be unavailable or less accessible in a paper portfolio, CV, or resume. For instance, a student who is listing the scholarships she has received can link to an online article in a college newspaper highlighting the award. Links to evidence like this bring depth and dimension to an ePortfolio.

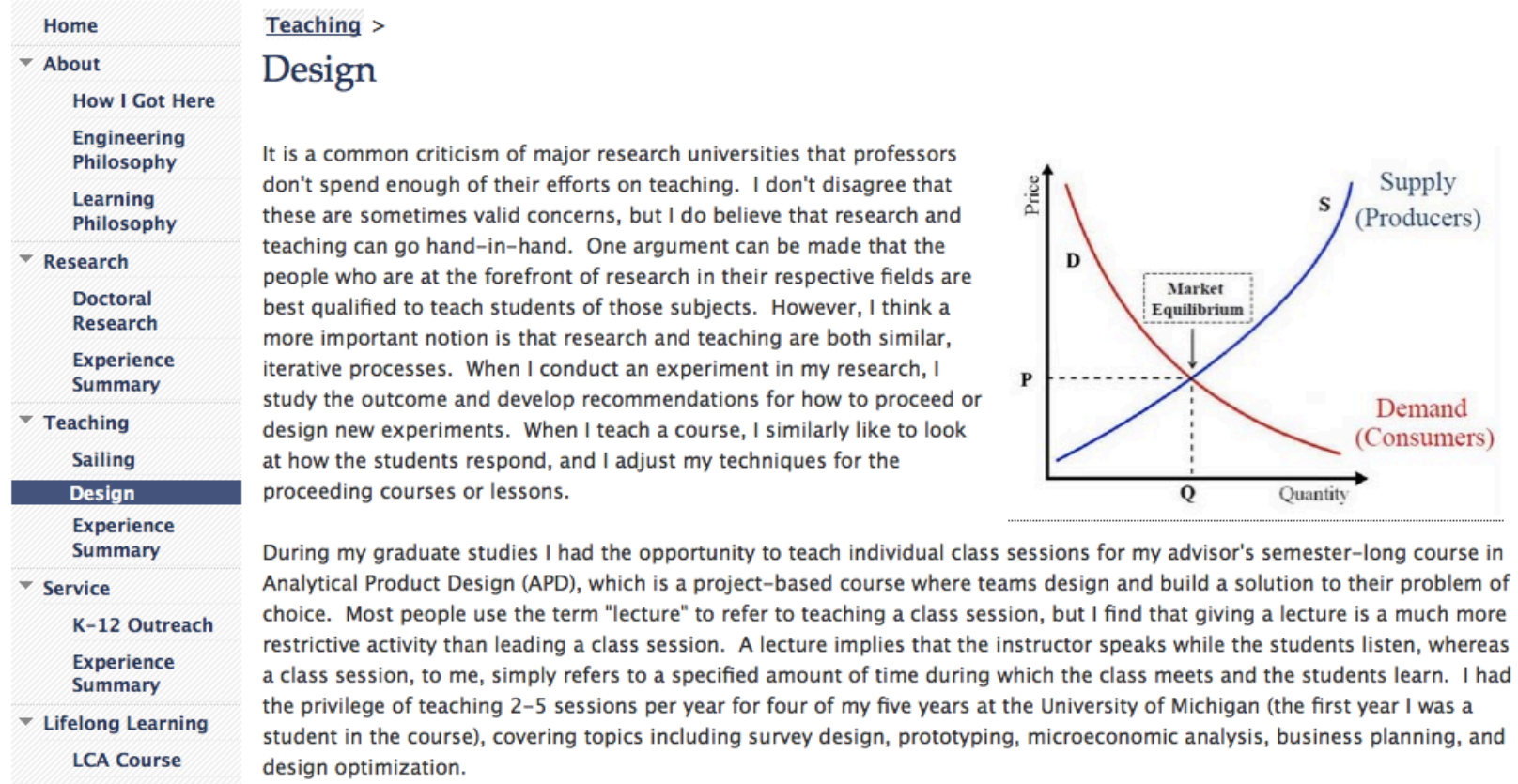

Figure 3. Example of ePortfolio page integrating items and themes across the portfolio. (Hoffenson, http://www.stevenhoffenson.com/teaching/design).

The technology that allows ease of linking can also lead to a level of integrated thinking in students that has long been a goal of many in higher education. For instance, when a piece of research can be easily linked to both an ePortfolio page about research and an ePortfolio page about teaching, students can identify linkages between the different subjects they study and the different areas of their lives more easily than before, achieving integration of concepts and identities in new ways.

Almost every ePortfolio tool-from webpage building tools to vended solutions-gives students the ability to share their ePortfolio in multiple ways, depending on their comfort level and purpose. The most common option is to share the entire ePortfolio publicly. But options also allow the student to invite a reader to view an Portfolio via an email address and requiring a log-in. Most tools also allow various pages within the ePortfolio to be shared or not shared at the student's discretion.

With these advantages, ePortfolios have made significant in-roads into higher education. However, most ePortfolio programs on campuses around the country are focused on creating ePortfolios that document student learning ${ }^{3}$. Almost every such ePortfolio receives a grade, as a part of a course, and many ePortfolios are a part of a larger assessment mission for the campus. For instance, a general education program may require all first year students to create an ePortfolio, showcasing their work toward the 
four program goals. These ePortfolios are graded as a part of that required first year course. But the ePortfolios are also read at the conclusion of the academic year by instructors outside the general education program, providing program assessment information for curriculum reform and data for accreditation.

One of the difficulties campuses have in implementing learning ePortfolios is with engaging students in the ePortfolio process ${ }^{3}$. Many students find it difficult to see how documenting their learning provides them with a tangible benefit. They see the ePortfolio as outside themselves, something that is "assigned" and they chafe against it, giving it only the most rote attention. Eportfolios created by engaged students are often deeply transformational. Subsequently, ePortfolios created by unengaged students are often just file cabinets of their work, reflected on at only a surface level. These ePortfolios built by reluctant students are not only not transformational to the student but they also are not indicative of the student's best work, which is what the assessor needs to be successful.

P2P ePortfolios provide a much-needed counterpoint to the learning ePortfolios most often being created in academe today. The ePortfolios created for P2P are focused on the student's career path. Ultimately, the students participating in P2P will use their ePortfolios in applying for jobs. (Most students in P2P are interested in teaching at the college level.) Lessons learned in engaging students in the P2P ePortfolios process may provide helpful insights to those directing learning ePortfolio programs.

P2P ePortfolios, by focusing on student's career aspirations, have student motivation built in. A professional ePortfolio allows students to present their knowledge and experience (with potential employers as their envisioned audience) in a more in-depth manner than a $\mathrm{CV}$ or resume allows. The link to an ePortfolio can then be shared in the bio area of social media sites. It can also be listed on a CV or business card, allowing students to actively curate their professional Internet presence. Because of these advantages related to the job market, students can readily see why engaging in creating their ePortfolio and really pouring effort into it will provide a benefit to them (increasing their chances of getting a job). They are often willing then - unprodded - to deeply engage in each weekly P2P ePortfolio step.

\section{Introduction of the P2P Curriculum}

This section describes the ePortfolio curriculum that we have developed and implemented in a pilot study. First we explain the structure of the curriculum and the processes that students use to create ePortfolios, then we describe feedback methods that are critical to supporting this kind of reflective work.

\section{A. Creating e-portfolios}

The P2P curriculum is structured in a series of small, scaffolded steps, with reflection embedded throughout the process of constructing ePortfolios. 


\section{Small Steps}

Across the nation, most ePortfolios being created by students are completed as an assignment for a course, and often very little detailed information is given to students about creating an ePortfolio. Students are told to create an ePortfolio and are perhaps directed to include a number of required assignments. The minimal level of information about what to do to create an ePortfolio typically leaves students overwhelmed by the task, unsure of how to start. This is a recipe for procrastination and a last minute rush of work-neither of which encourage the type of introspective reflection that makes an ePortfolio most valuable.

P2P, therefore, uses a curriculum that breaks down ePortfolio creation into 20 small steps (or 10 depending on whether a campus has chosen the year-long or term-long option). Each step is designed to be completed in less than 45 minutes. P2P students are asked to complete one step every week. The tasks focus on four areas (teaching, research, service, and lifelong learning) and consist of both written reflections and uploading evidence of accomplishments in those four areas.

Breaking down each ePortfolio task is key to the successful creation of a reflective ePortfolio because reflection takes time and requires "breathing space." If ePortfolio tasks are both spaced out over time and well-explained, students are less likely to procrastinate and can take advantage of the time provided to reflect, which increases the value of their ePortfolio.

\section{Scaffolded Steps}

Another important factor in the P2P curriculum is that ePortfolio creation activities are scaffolded. Scaffolding tasks can mean many things, but most often includes identifying relevant tasks, demonstrating tasks, and providing motivation ${ }^{4}$. Scaffolding breaks down each step of a task, demonstrates it, and rewards the completion of it ${ }^{5}$. When students are provided with scaffolded tasks, they perceive themselves as successful immediately, because they have succeeded with a small piece of the overall task. They have no internal barriers to continuing on with additional tasks. They look forward to additional personal success.

The ePortfolio tasks of P2P are heavily scaffolded. P2P identifies relevant tasks by creating a calendar of tasks and through providing a template for the reflections (with both a brief and an expanded option) that are required in about half of the P2P tasks. P2P demonstrates tasks by providing completed ePortfolio examples and by providing explanations of and readings on each task. P2P motivates students by specifically describing how various tasks are often required for certain positions in academe and in providing reference materials on the role of ePortfolios in the job market. Since the motivation to create a professional ePortfolio (that will help participants get a job) is built in, scaffolding allows student volunteers to successfully complete a task they are already interested in undertaking.

Some of the tasks P2P includes in its scaffolded curriculum include uploading numerous items that illustrate a student's professional accomplishments (including articles written 
for publication, course syllabi, teaching evaluations, and images of research and service completed).

\section{Embedded Reflection}

At the center of all true ePortfolios is reflection. When portfolios were first used by artists to collect and display their best work, any reflection that went into the choosing or creating of work was not evident in their portfolio. But in the 1970s and 1980s, when writing instructors began to adopt portfolios as assignments for their students, they added an element of reflection to the collection of student's best work ${ }^{6}$. Often, in creating portfolios, students were asked to document (to write about) why they chose a certain piece of writing for their portfolio. In addition, students were often asked to document the process they used to create the piece of writing they included-discussing drafts, feedback, changes, etc. It was in those "documenting your choices and progress" pieces that reflection as a part of the portfolio was born. Interestingly, writing instructors found that students often learned more about themselves as writers from writing the reflective pieces than from writing the original assignments.

Current ePortfolio champions advocate strongly for reflection ${ }^{7,8,9}$. They hypothesize that when students reflect on their past work-whether for a course or to get a job-it is then that they identify for themselves their own strengths, abilities, and accomplishments. Before creating an ePortfolio, students are often unaware of all they have accomplished, unaware of their own unique gifts. After creating an ePortfolio, they become more selfaware, and often-resultantly-much more self-confident, thus able to accomplish much more professionally.

The P2P curriculum asks students to reflect by asking students to find a piece of evidence of a professional accomplishment (a syllabi for a class taught, a paper published on research, etc.) and reflect (in writing) on it. The brief reflection template asks for reflection on specific themes regarding the artifact being showcased (skills gained, lessons learned, impact, etc.). The expanded reflection template asks for reflection on the implications the artifact has on teaching, asking students to make connections between scholarship and practice.

These reflections serve two purposes. First, they allow the student to more deeply explore their own accomplishments. Writing about an article they published or a course they taught often expands the student's professional identity in ways that simply having the experience doesn't. In addition, the reflection allows potential employers to learn more about the student's professional accomplishments than a line on a CV can tell.

\section{B. Providing Vital Feedback}

Effective feedback comes in the form of weekly comments from a facilitator along with peer feedback at significant stages in ePortfolio development.

\section{Weekly feedback from a facilitator}

Although students can create ePortfolios without feedback, giving students feedback on 
their ePortfolios is of value as a part of scaffolding (motivation/reward). It is also helpful in that it often shapes their future ePortfolio work. If given feedback that a particular reflection was engaging and helped the reader understand a professional accomplishment, the student receiving the feedback is not only much more confident as they continue to create their ePortfolio, but they are more likely to continue reflecting in a way that engages the reader.

There are two elements to effective feedback that are important to understand in the context of faculty giving feedback to students. Unfortunately, these elements are not well known and, therefore, most faculty do not follow them. Feedback, often, has become something students dread. In order for ePortfolio feedback to be helpful, it is critical that the two elements of successful feedback be present:

Successful feedback is formative ${ }^{10}$. When students get feedback as they are working, they are not only assured that they are being successful, but the feedback can help them work in the best direction. In the case of P2P, the ePortfolio tasks are broken down into weekly tasks, so the feedback must be weekly to be most effective. It needn't be lengthy, but if it is given every week, students are more likely to continue engaging with their weekly ePortfolio tasks.

One other advantage of weekly feedback from a facilitator is that it can reassure students who are unsure about posting their ePortfolio publicly. Every ePortfolio created ends up having a unique feature (such as using an article in a school newspaper about a scholarship as a portfolio artifact or a particularly appealing navigation language choice.) Pointing out that feature in feedback and asking the student's permission to share it with others-as an inspiration-often transitions students into viewing themselves as having something of value to share publicly and helps even the shyest students feel very comfortable sharing their ePortfolio. This is a necessary step for the professional ePortfolio, which must be shared in order to be of use in the job hunt.

Successful feedback is positive. Traditionally when faculty provide feedback on student writing, the focus is on what could be improved. Although this type of evaluative feedback is one type of feedback, it is over-used in academe, and, in ePortfolio work, "evaluation and advice are not what writers need most." 11 Other forms of feedback-for instance feedback that tells the student what aspects of a reflection are most engaging - can be more helpful to a student's confidence than evaluative or judgment feedback is. Providing feedback about what works in a piece of student writing reinforces positive behavior.

When evaluative feedback is provided, it is vital that the student be in control of that feedback. In P2P, one of the 20 tasks is for students to write a "feedback request" detailing their own questions about their ePortfolio. They go on to share this request during peer feedback.

Because most students have only received feedback on their writing in school, and because that feedback has been, overwhelmingly, of an evaluative nature, many students do not welcome receiving feedback. But when feedback is overwhelming positive-focused on 
describing what works rather than on criticism - creating the ePortfolio becomes something that the student is successful at and they are more likely to remain engaged in their weekly tasks. It is only when students are involved and invested in ePortfolio creation that they ePortfolio becomes a transformative learning experience and is most likely to be a true representation of their best work. Positive, non-evaluative feedback not only helps a student continue to write reflections that engage the ePortfolio reader, but allows the student to perceive the ePortfolio process positively.

\section{Peer feedback}

Another type of feedback that can be very helpful to students is peer feedback, provided it occurs in a structured setting. Peer feedback can be much more motivational to students than faculty feedback. But, like developing the ePortfolio itself, the feedback experience must be scaffolded in order to be most effective. ePortfolio programs, like Turns' at University of Washington, that incorporate peer feedback in the portfolio design process often see a deeper level of engagement and success ${ }^{12}$.

In order to utilize peer feedback easily, a public gallery of ePortfolios must be available. Some students may be reluctant to make their ePortfolio public. But a public ePortfolio has innumerable advantages, not only in terms of professional representation on the Internet, but also in terms of the feedback it enables students to receive.

Viewing other ePortfolios (in a public gallery) is incredibly helpful to students. It often allows them to see formatting choices they hadn't previously imagined. Viewing each other's ePortfolios often results in ePortfolios that are, visually, much more engaging than ePortfolios created in isolation. In addition to having students view each other's ePortfolios, having students give formal, structured feedback to each other is valuable as well.

Peer feedback really only works if it is structured. One approach to structured peer feedback is to have each student create a written feedback request. This is effective because most students are very hesitant to give honest feedback to other students. The feedback they write, then - out of desire to avoid criticizing a fellow student-is on a surface level and often useless. But when the student themselves write a feedback request, documenting the questions they have about their own portfolio (such as "does this photo help explain the project?" or "did you understand that you should click the link to read the article?" or "did writing about the mistake I made in my research make me sound unprofessional?"), then other students have permission to provide honest and helpful descriptions of their reactions to an ePortfolio. When using peer feedback, the written feedback request is invaluable.

\section{Introduction of Analysis Methods}

\section{A. Rubric}

In addition to providing a curriculum that guides students in developing their ePortfolios, P2P also provides students with a rubric. Often students find understanding the end goal of a project easier if they are given a rubric. 
The P2P rubric is a four-level rubric (Not Recommended, Basic, Thorough, Outstanding). It is written in order to be able to be used on a variety of campuses, regardless of the culture of the campus. The rubric addresses ePortfolio content (such as evidence) as well as ePortfolio mechanics and appearance (such as navigation and photos). Although the rubric is written by P2P staff, a feedback process was used in the Fall of 2011 to solicit input on the rubric from three P2P campuses. The rubric will be pilot-tested in Fall 2012 and ready for final release in 2013.

\section{B. Coding for Engagement, Reflection, and Identity}

In the summer of 2012, the text and appearance of ePortfolios from four campuses will be coded to analyze engagement, reflection, and identity.

It is vital to analyze student engagement with their ePortfolios for two reasons. First, in the young field of ePortfolios, student engagement with their own ePortfolio has rarely been studied. Understanding more about student engagement would allow a revision of the P2P curriculum so that future students could engage more deeply in their ePortfolios, thus allowing them to create more effective ePortfolios. Data about student engagement could also be used by those outside P2P to improve ePortfolio programs across the country.

The subject of student reflection has received some attention in the field of ePortfolios, but additional data is needed in order to be able to accurately and thoroughly articulate the elements of effective student reflection. Student reflection in ePortfolios is often spoken of as being the key to a successful ePortfolio, but currently, only the publication of the AAC\&U VALUE Rubric on Integrative Learning provides published documentation of the widely accepted elements of reflection. The field of ePortfolios has not used a data-based approach to student reflection ${ }^{13}$; so, the P2P coding on this subject could provide valuable data about student reflection markers and possible correlations between student reflection and the other subjects of P2P (such as engagement and identity.)

Identity of future professionals is one of the main foci of P2P. Although much work has been done on the subject of identity development in teachers and in professors, very little work has been done on a professional's identity in their home discipline, as it is integrated with their identity as an instructor in a higher education setting. The coding done on P2P ePortfolio will provide data that will help chart future directions on research. Just as we have almost no data on student engagement relating to ePortfolios, there is also a data deficit in the area of professional identity integration.

\section{Survey}

During the first six months of this study, Louis and McNair developed a survey to explore how graduate students view their professional roles, both as graduate students and future faculty members ${ }^{2}$. Specifically, the survey focused on how students perceived their roles as teachers, researchers and lifelong learners. Furthermore, the survey probed into these perceptions in terms of how students viewed these roles now and in the future, and in terms of what students thought was and would be expected of them, what they wished for now and in their future careers, and what their current experiences actually were. 
Since the goals of the survey were to define and measure constructs such as identity and lifelong learning, a theoretical lens was identified to undergird the project and assessment methods were used to establish validity and reliability. Ashforth's ${ }^{14}$ role identity model was selected as a theoretical framework because it takes into account the multi-layered and transitional nature of identity, and also because it is focused on professional identities. Ashforth suggests that at any one moment a person holds a certain identity that is composed of multiple roles and that there are often transitions between roles that can be challenging to individuals. According to Ashforth, "a role is defined simply as a position in a social structure" (p. 4), but this position is complex and encompasses the "goals, values, beliefs, norms, interaction styles, and time horizons that are typically associated with a role" (p. 6). This lens of identity as an intersected construct guided the survey design to allow for overlap and dissonance in responses, which we believe is a realistic finding.

Through an iterative refinement process, the construct of the survey was developed and validated. The steps involved choosing an appropriate theoretical framework, defining the construct, reviewing survey items with experts, selecting an appropriate population to validate the tool, and analyzing the results through a confirmatory factor analysis followed by an analysis of the results using simple correlations. Three populations were surveyed, including graduate students in departments of engineering, engineering education, and education.

The results of this study show that there is a weak alignment between the current actual role of students and what they perceive they will be doing in their future profession. There is also weak alignment between actual and desired roles in their graduate experiences. These initial results indicate that both education and engineering students may benefit from enhanced experiences in teaching and/or programmatic support of teaching roles and activities. We interpret this to mean that enhanced ePortfolio processes, such as the one we have developed in $\mathrm{P} 2 \mathrm{P}$, could help students navigate priorities and role changes over time, since actual, expected, and desired roles are often at odds. For our purposes, ePortfolio projects in which students present artifacts such as teaching statements, course development, assessment work, and teaching evaluations may hold promise in helping students build and embrace roles as teachers today and in their future careers.

\section{Conclusion}

In this paper we have introduced initial steps at the first-year mark of a 5-year research project designed to explore engineering graduate students' identities as both engineers and educators. We have also described our early products: a survey to measure constructs of professional identity, a curriculum to guide graduate students and faculty facilitators in developing professional and reflective ePortfolios, and a rubric to help students and facilitators evaluate progress in both the content and technical components of ePortfolios.

Results from the initial survey indicated that a misalignment exists between graduate experiences and the professional goals of graduate students. Theoretically, numerous researchers have characterized the construct of identity as fluid, multi-layered, socially constructed, and complex. Thus, initiatives such as ePortfolios-which guide students to 
present their best work in reflectively constructed narratives of their achievements and goals - may be powerful tools in graduate programs. However, due to the autonomous nature of both graduate students and ePortfolio ownership, typical processes that position ePortfolios in contexts of grading may not be effective. Following this rationale, we have created a curriculum that grants ownership to graduate students while supporting their work with positive guidance as they build their public professional personas.

Future work will pair the quantitative survey with qualitative analysis of ePortfolios produced by students in the $\mathrm{P} 2 \mathrm{P}$ program. Results will be used in a continual improvement cycle to refine the curriculum and expand to other university settings. Finally, all products are shared publicly for use by faculty and students actively pursuing goals of promoting effective engineering education and throughout higher education. Through both new research and the establishment of best practices over the course of this grant, we hope to work within the field of engineering education to graduate members of the professoriate who are true reflective practitioners and who will begin their careers already able to leverage scholarly teaching approaches to contribute to the cycle of experience, learning, and practice that improves the future of engineering.

\section{Acknowledgment}

This material is based upon work supported by the National Science Foundation under Grant No. NSF EEC-1055595. Any opinions, findings, and conclusions or recommendations expressed in this material are those of the author(s) and do not necessarily reflect the views of the National Science Foundation. The authors would also like to thank the study participants for their participation.

\section{Works Cited}

1. L. H. Jamieson and J. R. Lohmann, "Creating a culture for scholarly and systematic innovation in engineering education: Ensuring U.S. engineering has the right people with the right talent for a global society. Phase 1 Report," American Society for Engineering Edcuation, Washington, DC, 2009.

2. R.A. Louis and L.D. McNair, "Graduate student identity in engineering and education: The creation of an identity construct." ePIC 2011: ePortfolio and Identity Conference. London, England: July 11-13, 2011. Available online at: http://www.epforum.eu/ proceedings/epic-2011-1/view.

3. D. Tosh, T. P. Light, K. Fleming, and J. Haywood, "Engagement with Electronic Portfolios: Challenges from the Student Perspective." Canadian Journal of Learning and Technology, 31(3), online version, 2005.

4. E. M. Rodgers, "Interactions that Scaffold Reading Performance." Journal of Literacy Research, 36(4), 501-532, 2004. http://jlr.sagepub.com/content/36/4/501.full.pdf+html.

5. J.S. Bruner, R. Rose, and P.M. Greenfield, et al., Studies in cognitive growth. Oxford, 
England: Wiley, 1966.

6. P. Belanoff, "Portfolios and Literacy: Why?" New Directions in Portfolio Assessment: Reflective Practice, Critical Theory, and Large-Scale Scoring. Portsmouth: Boynton/Cook, 1994.

7. M. Peet, S. Lonn, P. Gurin, K. P. Boyer, M. Matney, T. Marra, S. Himbeault Taylor, A. Daley, "Fostering Integrative Knowledge Through ePortfolios." International Journal of ePortfolio $1[1], 2011$.

8. H. L. Chen and T. Penny Light, Electronic Portfolios and Student Success: Effectiveness, Efficiency, and Learning. Washington DC: Association of American Colleges and Universities, 2010.

9. B. Eynon, "Connect to Learning: ePortfolio, Engagement, and Student Success," 2010. http://www.lagcc.cuny.edu/connections/

10. B. Olds and R.L. Miller, "Using formative assessment for program improvement." In Designing Better Engineering Education Through Assessment (edited by J.E. Spurlin, S.A. Rajala, and J.P. Lavelle). Sterling, VA: Stylus, 266-284, 2008.

11. P. Elbow and P. Belanoff, "Cover Letter" Sharing and Responding. Boston: McGraw Hill, 2000.

12. M. Eliot and J. Turns, "Constructing Professional Portfolios: Sense-Making and Professional Identity Development for Engineering Undergraduates." Journal of Engineering Education, 100(4), 630-54, October 2011.

13. P.C. Abrami and H. Barrett, "Directions for Research and Development on Electronic Portfolios." Canadian Journal of Learning and Technology, 31(3) Fall 2005.

14. B. E. Ashforth, Role Transitions in Organizational Life: An Identity-Based Perspective. Mahwah, NJ: Lawrence Erlbaum Associates, Inc. 2001. 